\title{
Rendement en risico in de jaarrekening: een pleidooi voor marktwaarde
}

\section{Drs. J. G. Groeneveld}

\subsection{Inleiding ${ }^{1}$}

In 1971 was de wetgeving voor jaarrekeningen van ondernemingen vooral geënt op het geven van inzicht in waarde en winst van ondernemingen. Waarde en winst waren de twee elementen waar het toen om draaide. Daarmee was deze benadering in hoofdzaak gericht op inzicht in rendement en rentabiliteit van het geïnvesteerde eigen vermogen.

Twintig jaar geleden was die oriëntatie misschien toereikend, hoewel ook toen al kritische kanttekeningen werden geplaatst. Voor zover zij toereikend was, is zij dat mijns inziens op dit moment niet meer. Onder het motto dat rendement pas in combinatie met risico kan worden gewaardeerd, wil ik in het volgende enkele argumenten naar voren brengen voor een wetgeving waarmee, meer dan op dit ogenblik het geval is, naast inzicht in rendement en vermogen ook inzicht kan worden gegeven in de risico's waarmee een verslaggevende onderneming wordt geconfronteerd en in de wijze waarop de betreffende ondernemingsleiding daarmee omgaat. Wat mij betreft, kan deze argumentatie als een pleidooi voor zo'n wetgeving worden opgevat.

\subsection{Opzet}

De lijn die ik in dit betoog zal volgen, begint bij het rapport van de Commissie Verdam en de op dit rapport gebaseerde Wet op de Jaarrekening. Rapport en Wet krijgen een kader in de commen- taren en omstandigheden van die tijd. Vervolgens wordt de sprong gemaakt naar de Nederlandse wetgeving van 1991 en zal worden gewezen op enkele omstandigheden zoals die zich in de tussenliggende kwart-eeuw hebben ontwikkeld. $\mathrm{Na}$ deze analyse, die dient ter ondersteuning van het gekozen uitgangspunt, kan worden vastgesteld dat de mogelijkheden die bestaande conventies bieden niet toereikend zijn om in voldoende mate risico's en de manier waarop de ondernemingsleiding daarmee omgaat in de jaarrekening tot uitdrukking te brengen. Op grond daarvan wordt dit artikel afgesloten met een voorstel tot wetswijziging.

\subsection{Uitgangspunt}

Voor mijn betoog ga ik uit van de tegenstelling die in de figuren 1 en 2 wordt geschetst. Bij voorbaat zij toegegeven dat de gecreëerde tegenstelling scherper is dan wat de werkelijkheid te zien geeft: in de jaren zestig was het niet zo dat risicovoorstellingen in de jaarrekening geheel mochten ontbreken. Maar veel meer dan nu werd in die tijd waarde gezien als een functie van winst in plaats van, zoals tegenwoordig, als een functie van winst $^{2}$ en risico.

Drs. J. G. Groeneveld, registeraccountant, studeerde Bedrijfseconomie (1970) en Accountancy (1973) aan de Universiteit van Amsterdam respectievelijk de Katholieke Universiteit Brabant. Momenteel als universitair hoofddocent verbonden aan de Erasmus Universiteit Rotterdam. 


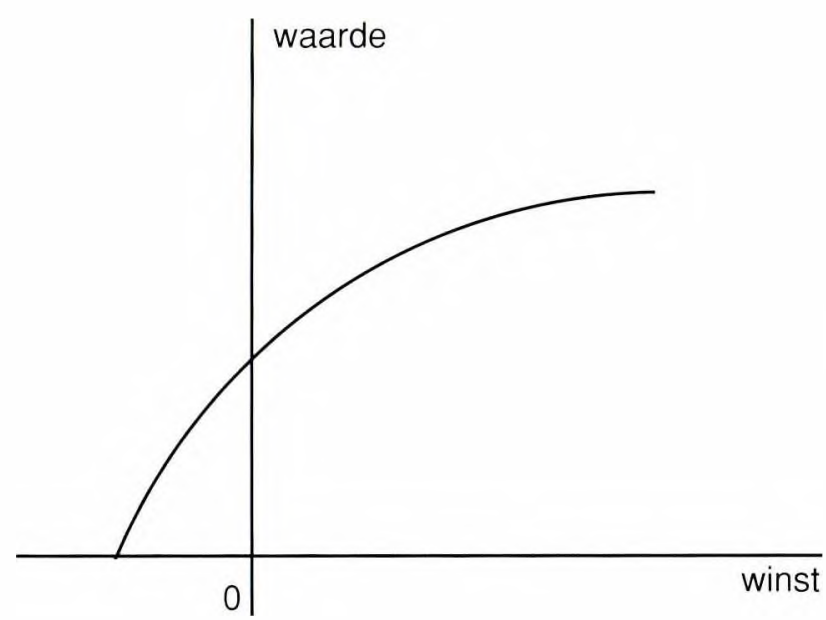

Figuur 1: Waarde als degressief toenemende functie van de winst

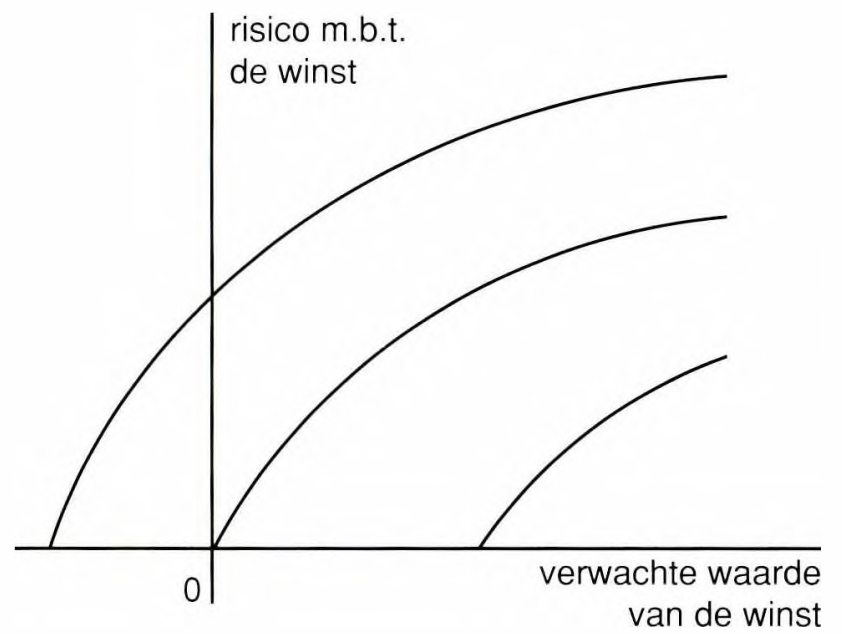

Figuur 2: Waarde voorgesteld in indifferentiecurven als functie van de verwachte waarde van de winst en van het risico met betrekking tot de winst

De 'waarde en winst'-oriëntatie van weleer schiet vandaag de dag tekort. Dat geeft een onbehagen dat niet in elk opzicht nieuw is. In 1965 - in de aanloop naar de Wet op de Jaarrekening schreef Goudeket in een commentaar op het rapport van de Commissie Ondernemingsrecht (naar haar voorzitter de Commissie-Verdam genoemd): '...indien men van de gepubliceerde jaarrekeningen kennis neemt, komt men nog veelvuldig tot de conclusie dat, alhoewel een goedkeurende verklaring aanwezig is, niet het inzicht wordt ver- strekt dat ten minste mag worden verwacht' (Goudeket, 1965).

\subsection{Het rapport van de Commissie-Verdam}

In zijn rede bij de installatie van de CommissieVerdam wilde de toenmalige minister van Justitie, Mr. Beerman, 'dat de jaarstukken - met name de balans en de winst- en verliesrekening - een duidelijk (cursivering Groeneveld) beeld geven van de gang van zaken in de naamloze vennootschap'.

Het ging de Commissie-Verdam erom 'de belanghebbenden een reëel (cursivering Groeneveld) inzicht in de onderneming te geven'. De openheid der betrekkingen tussen het bestuur en de kapitaalverschaffers enerzijds en tussen het bestuur en de werknemers anderzijds kreeg in het commissie-rapport in de allereerste plaats vorm in voorstellen met betrekking tot de jaarverslaggeving (Bergsma, 1965). De Commissie stelde trouwens voorop, dat een goede verslaggeving niet alleen in het belang is van de aandeelhouders, maar ook van de obligatiehouders en andere crediteuren, het beleggend publiek, potentiële leveranciers en afnemers, certificaathouders en werknemers.

Het ministeriële 'duidelijke beeld van de gang van zaken', respectievelijk het 'reële inzicht in de onderneming' kregen in het commissierapport uitwerking in de eis van het voorgestelde artikel 2 dat de jaarrekeningen van de betreffende ondernemingen een zodanig inzicht geven 'dat een verantwoord (cursivering Groeneveld) oordeel kan worden gevormd omtrent het vermogen en de rentabiliteit van de onderneming, alsmede omtrent haar solvabiliteit en liquiditeit'. Dit artikel vormde samen met het door de Commissie voorgestelde artikel 3 de kern van de ontworpen wet. In dat voorstel luidde artikel 3:

'1 De balans met de toelichting daarop geeft getrouw en stelselmatig de grootte en de samenstelling van het vermogen van de onderneming op het einde van het boekjaar weer.

2 De winst- en verliesrekening met de toelichting daarop geeft getrouw en stelselmatig de grootte en de samenstelling van het resultaat van de onderneming over het boekjaar weer'. 


\section{MAB}

Voor ons doel moet bovendien worden verwezen naar artikel 5 van het Commissie-ontwerp dat eveneens tot de kern daarvan kon worden gerekend (G. L. Groeneveld, 1968). Met betrekking tot de waarderingsgrondslagen voor activa en passiva wordt in dit artikel het voorstel gedaan dat deze moeten voldoen 'aan normen die in het maatschappelijk verkeer als aanvaardbaar worden beschouwd' (Commissierapport, 1965).

\subsection{De wet op de Jaarrekening}

In de Wet op de Jaarrekening van 1971 bleven deze artikelen nagenoeg ongewijzigd. Rekening houdend met de aard van een jaarrekening is in de wettekst wel de eis van het verantwoorde oordeel omtrent de solvabiliteit en de liquiditeit van de verslaggevende onderneming beperkt. Letterlijk staat er: '...voor zover de aard van een jaarrekening dat toelaat...'.

\subsection{Kanttekeningen}

Zoals gezegd, er werden al op dat moment kanttekeningen geplaatst. Met betrekking tot risico werden bijvoorbeeld de volgende opmerkingen gemaakt.

- In zijn preadvies voor de accountantsdag van 1967 gaf Burgert in een cijfervoorbeeld blijk van zijn moeilijkheden met het 'ex post'-karakter van de jaarrekening. Hij merkte op: 'In dit cijfervoorbeeld lijkt alles zo aardig te kloppen, dat men zich kan afvragen, of daar nog wel discussie over mogelijk is', om te vervolgen: 'Men vergete niet, dat het ex post is opgemaakt, of - wat op hetzelfde neerkomt - dat het ex ante met 'perfect foresight" is opgemaakt" (Burgert, 1967). Naar aanleiding van zijn voorbeeld stelt Burgert vast: 'Zou men de achtereenvolgende jaarrekeningen op deze wijze opstellen, dan stelt men naar onze mening als exact en objectief voor wat in feite uitermate onzeker en subjectief is'. Burgert laat het niet bij deze ene waarschuwing: '...het berekenen van het verteerbaar inkomen met juistheid en ondubbelzinnigheid is in de dynamische werkelijkheid een illusie. Vooral accountants moeten ervoor waken illusionaire voorstellingen juiste voorstellingen te noemen'.
In de verwijzing naar dynamiek zie ik een verwijzing naar risico dat met een 'ex post'-benadering als spiegelbeeld van 'perfect foresight' zou worden weggeschreven. Wat mij betreft, maar dat is in dit kader terzijde, kan nog worden opgemerkt dat identificering van 'perfect foresight' met een 'ex post'-benadering zelfs over de kennis van het verleden te veel illusie geeft.

- Deze problematiek rond verleden en toekomst krijgt vervolg bij Sanders, G. L. Groeneveld en Burgert. Zij brengen 'de tweeslachtigheid (naar voren) van enerzijds het rapporteren over in het verleden afgesloten transacties en anderzijds de aanwezigheid van allerlei produktiemiddelen, die hun eigenlijke waarde aan toekomstige opbrengsten ontlenen' (Sanders, Groeneveld en Burgert, 1972, p. 29).

Al naar aanleiding van het wetsontwerp had Ysselmuiden het belang onderstreept van een verslaggeving waaruit 'de balanslezer zich een oordeel (kan) vormen over de toekomstige ontwikkeling' (Ysselmuiden, 1968, p. 18). Hij zag hierin een tegenstelling met het standpunt van de minister. Volgens hem lag daaraan 'de gedachte ten grondslag, dat belanghebbenden - dat zullen hier de aandeelhouders zijn - slechts het rendement op hun investering moeten kunnen beoordelen'.

Ik kan mij niet aan de indruk onttrekken dat ook Ysselmuiden in het wetsvoorstel waarde zag gepresenteerd als een enkelvoudige functie van winst.

- Over dynamiek gesproken: volgens G. L. Groeneveld was de Commissie-Verdam te ver gegaan: liquiditeit vraagt meer een dynamisch gezichtspunt en niet een momentopname.

De in de wettekst aangebrachte beperking met betrekking tot de beoordeling van liquiditeit en solvabiliteit zal hem dan ook zijn bevallen.

Ook over de voorstelling van waarde werden behartenswaardige opmerkingen gemaakt. Ter ondersteuning van mijn stellingname heb ik de volgende citaten gekozen.

- 'Het berekenen van afschrijvingen is een zodanig arbitraire zaak, dat de boekwaarde tot een 


\section{MAB}

uitermate weinigzeggend getal wordt gereduceerd' (Sanders, Groeneveld, Burgert, 1972, p. 103).

Zelfs los van het kader waarin ik gebruik maak van dit citaat verdient het aandacht. Wij weten allemaal dat het zo is, maar als argument om het anders te doen krijgt het opmerkelijk weinig aanhang.

- Sanders, Groeneveld en Burgert vinden het '...'merkwaardig' dat de wet niets zegt over de rubricering. Het is immers juist ook de rubricering die in belangrijke mate bijdraagt tot een goed inzicht' (SGB, 1972, p. 94).

Inderdaad is dat merkwaardig. Een model - en de jaarrekening is een financieel-economisch model van de organisatie - bestaat uit elementen en relaties daartussen. Een aantal relaties zou in rubricering tot uitdrukking hebben kunnen worden gebracht. Bij afwezigheid daarvan kan, wanneer het model wordt teruggelezen, schade ontstaan aan het beeld van de werkelijkheid dat op basis van het model moet worden verkregen.

Samengevat komt het erop neer dat door een aantal zeer gezaghebbende auteurs al bij de totstandkoming van de Wet op de Jaarrekening is gewezen op:

- de te grote betekenis die aan boekwaarde wordt toegekend;

- het te statische karakter van de vereiste verslaggeving;

- de te eenzijdige oriëntatie daarvan op het verleden;

- de te fragmentarische voorstelling van elementen daarin.

\subsection{Situatie in 1971}

Ondanks de kritiek kwam deze wetgeving vrijwel ongewijzigd tot stand. Voor het 'waarom' kan worden gewezen op het bestaande verlangen naar objectiviteit, op produktgerichtheid van ondernemingen, op de toen betrekkelijk statische omgeving, op de relatief eenvoudige informatietechnologie en op een financieel instrumentarium dat veel minder was ontwikkeld dan het instrumentarium dat tegenwoordig ter beschikking staat.
- Het verlangen naar objectiviteit zal een grote rol hebben gespeeld. De eis van objectiviteit wordt steeds als argument naar voren gebracht. Met betrekking tot 'financial accounting' gebeurt dat met nog meer kracht dan wanneer het 'management accounting" betreft. En men is nu eenmaal gewend om de gewenste objectiviteit wel in het verleden te vinden en niet in de toekomst. Het gebruik van 'perfect foresight' als spiegel van het verleden is daarvan een voortreffelijk voorbeeld. In die gedachtengang genereert het verleden feiten. 'Logisch' dus dat objectiviteit tot retrospectie leidt en tot een verslaggeving die vooral daarvan de uitkomst is.

- Ondernemingen waren in het algemeen nog in hoofdzaak produktgericht. Waardering tegen kostprijzen was toen logischer dan, bij de meer marktgerichte ondernemingen van nu, waardering tegen marktwaarden. Gekoppeld aan de objectiviteit (lees: de verifieerbaarheid) van historische prijzen lag de toereikendheid van waardering tegen historische prijzen zeer voor de hand.

- De omgeving waarin werd ondernomen, had minder risico in petto dan tegenwoordig het geval is. De veronderstelling van een 'going concern" was voldoende voor extrapolatie van het historische beeld.

- De informatietechnologie van de jaren negentig (automatisering en communicatie) moest in die tijd nog in belangrijke mate worden ontwikkeld. Voor de efficiency van markten en daarmee voor de toepasbaarheid van marktwaarden maakt dat letterlijk een wereld van verschil. Alternatieve waardering tegen marktwaarde was toen geen reële optie. Natuurlijk waren ook de interne informatiesystemen, de boekhouding en de administratie, nog niet opgewassen tegen de eisen, die wij daaraan vandaag de dag stellen.

- Op het terrein van het financiële management van ondernemingen waren nog niet de innovaties gedaan die 'financial accountants" tegenwoordig in verlegenheid dreigen te brengen.

Ervan uitgaande dat deze factoren de omstandig- 


\section{MAB}

heden van toen getrouw weergeven, waren de kanttekeningen die bij de wetgeving werden gemaakt weliswaar van principieel belang, maar legden praktische belangen daarbij nog geen groot gewicht in de schaal.

\subsection{De wet in 1991}

Inmiddels is dat gewicht van praktische belangen aanzienlijk toegenomen. Het hoeft dan ook geen verwondering te wekken dat in de afgelopen twintig jaar de wettekst verandering en aanvulling heeft ondergaan. Voor de kern van de wet noem ik enkele ontwikkelingen.

- In 1983 is het 'Besluit modellen jaarrekening' gepubliceerd. Dit besluit dient tot vaststelling van modelschema's voor de inrichting van jaarrekeningen. Met het oog op rubricering van afzonderlijke posten in de jaarrekening en het hieraan te ontlenen inzicht is dit van groot belang.

- $\mathrm{Er}$ is een toekomstparagraaf in de wet gekomen. Onder voorbehoud geldt de verplichting om in het jaarverslag mededelingen te doen omtrent de verwachte gang van zaken, gespecificeerd naar investeringen, financiering, personeelsbezetting en omstandigheden waarvan de ontwikkeling van de omzet en de rentabiliteit afhankelijk is. Mededelingen moeten worden gedaan omtrent de werkzaamheden van de onderneming op het gebied van onderzoek en ontwikkeling (BW boek 2, titel 9, artikel 391).

- In een ander opzicht is de cirkel gesloten. In artikel 362 is naast de vanouds bekende termen 'getrouw' en 'stelselmatig' de term 'duidelijk' teruggekeerd waarmee in 1960 de minister de Commissie-Verdam installeerde. Ook overigens is de formulering van artikel 362 (het oude artikel 3 WJO) enigszins gewijzigd. Daarin is nu niet alleen sprake van de grootte en samenstelling van vermogen, respectievelijk winst of verlies, maar ook van de actief- en passiefposten, respectievelijk de baten en lasten waaruit vermogen en resultaat zijn samengesteld.

De ontwikkeling in de wet lijkt er vooral een te zijn van meer specificatie en meer structurering.

\subsection{De situatie in 1991}

Terzijde van de wet zijn de ontwikkelingen in de praktijk stormachtig geweest. Vergelijkenderwijs is dat al enigszins genoemd.

- Van 'produktgericht' werden ondernemers 'marktgericht' en zelfs 'afnemersgericht". De huidige oriëntatie op markten is niet alleen manifest voor de verkoopmarkten van ondernemingen, maar ook voor de vermogensmarkten. 'Investors relations' worden gecreëerd en gekoesterd. Beursnoteringen worden haast angstvallig in het oog gehouden. Het 'onbegrip' van de beurs zoals zich dat volgens menig 'president directeur' in een te lage beurskoers uit, wordt vanuit de praktijk tegemoet getreden met een pleidooi voor het tonen van de 'embedded value' van de onderneming (Van der Meer, 1990) en voor waardering van merken op de balans. 'Break up values' baren managers zorg omdat in de werking van de 'market for corporate control' niet voor niets een correctiemechanisme kan worden gezien voor eventuele eigen inefficiëntie.

- Automatisering en communicatietechnologie hebben in de beschouwde periode een revolutionaire ontwikkeling doorgemaakt. Dat kan aan de hand van enkele voorbeelden worden geillustreerd.

- Vijfentwintig jaar geleden moesten computerruimten met stofjas worden betreden.

- Hoewel nu al niet meer weg te denken, is de fax pas de laatste jaren operationeel geworden.

- Kopieermachines zoals wij die nu kennen, maakten pas een kwart eeuw geleden, dus min of meer gelijk met de Wet op de Jaarrekening, hun entree.

- Zelf verplaatsen wij ons niet in de spreekwoordelijke 'tachtig dagen" maar in tachtig uren rond de aarde. En een boodschap die wij van Amsterdam naar New York, van New York naar Tokio en van Tokio weer naar Amsterdam sturen, hoeft er niet eens 80 seconden over te doen $^{3}$. Met telematica, als integratie van telecommunicatie en informatica, mogen wij stellig nog meer verwachten. 


\section{MAB}

- Dat gedurende de laatste decennia de ondernemingen met meer risico zijn geconfronteerd, heeft uiteenlopende oorzaken.

- Monetaire autoriteiten grijpen vaker naar het rentewapen.

- Valutakoersen, denk aan de Amerikaanse dollar, maken flinke 'uitslagen" sinds in 1973 de vaste wisselkoersen zijn losgelaten.

- De prijs van aardolie was bij herhaling zodanig in beweging dat van een oliecrisis kon worden gesproken.

- En dan waren er nog de beurskrachs die in de afgelopen jaren voor opschudding hebben gezorgd.

Communicatie- en informatietechnologie, risico en marktgerichtheid zijn drie factoren, die in hoge mate de mogelijkheid en de wenselijkheid bepalen van een adequaat financieel management van ondernemingen. Risico is een knelpunt geworden met een schaduwprijs, die het voor financiële instellingen aantrekkelijk maakte om nieuwe financiële instrumenten te ontwikkelen. Dat is dan ook in hoge mate gebeurd. De financiële markten zijn er in principe vollediger, perfecter en efficiënter door geworden. Dat betekent dat de prijsvorming op die markten aan betrouwbaarheid heeft gewonnen. Bovendien betekent het dat een ondernemer over een arsenaal van instrumenten beschikt om met risico om te gaan. Zodoende kunnen op verschillende manieren en in verschillende mate verschillende risico's door hem worden verhandeld of gehedged. Het beleid dat hierin wordt gevoerd, heeft belangrijke gevolgen voor de hoogte van zijn vermogenskosten en dus ook voor de waarde, die op een bepaald moment op verschillende markten aan de onderneming of aan onderdelen daarvan wordt toegekend.

\section{Risico in de jaarrekening}

De vaststelling dat waarde een functie is van zowel rendement als van risico, houdt in dat het noodzakelijk is om niet alleen het rendement maar ook de risicopositie van een onderneming te beoordelen. $\mathrm{Er}$ is dus reden genoeg om na te gaan op welke wijze met onze huidige wetgeving risico's in de jaarrekening naar voren kunnen worden gebracht.

Traditionele mogelijkheden om in de jaarrekening informatie over risico te bieden, of tenminste in aanmerking te nemen, zijn de volgende.

- De beoordeling van liquiditeit en solvabiliteit voorzover de aard van de jaarrekening dat toelaat, is al genoemd. In het algemeen kan de mate van risico mede worden afgeleid uit de financieringsstructuur van de onderneming.

- De toekomstparagraaf in het jaarverslag geeft wellicht inzicht in de risicopositie.

- De in veel gevallen impliciete 'going concern'veronderstelling dringt eventuele gedachten aan snelle teloorgang van de onderneming naar de achtergrond.

- Toepassing van het voorzichtigheidsbeginsel, waarin bij uitstek met de zwarte zijde van risico wordt gerekend, geeft per definitie, zij het eenzijdig, uitdrukking aan risico.

- Toepassing van het realisatiebeginsel stelt winstneming uit tot een moment (vaak levering of facturering) dat samenhangt met een verkooptransactie. Voor voorraadresultaten geldt het oude spreekwoord: geen winst zonder ruil.

- Uit het gebruik van bepaalde afschrijvingsmethoden of -termijnen kan eventueel voorzichtigheid worden afgeleid.

- In de toelichting op de balans kunnen verzekerde waarden worden genoemd.

- Voorzieningen worden gevormd tegen 'verplichtingen en verliezen waarvan de omvang op de balansdatum onzeker is, doch redelijkerwijs is in te schatten'. Voorzieningen kunnen eveneens worden gevormd tegen 'op de balansdatum bestaande risico's ter zake van bepaalde te verwachten verplichtingen of verliezen waarvan de omvang redelijkerwijs is te schatten' (BW boek 2, titel 9 artikel 374).

- Voor de oordeelsvorming omtrent risico-artikel 375 ook interessante mogelijkheden. Ik noem daarvan de vereiste specificaties van schulden en vooruitbetalingen, van looptijden en rentepercentages, van de gestelde zakelijke zekerheden en van achterstellingen.

- Artikel 376 vereist inzicht in geboden zekerheid 


\section{MAB}

voor schulden van anderen en in risico voor verdisconteerde wissels en cheques.

- Artikel 383 vraagt informatie over bepaalde garanties.

- Verliesrisico's waarvoor geen voorziening is getroffen, kunnen in de toelichting worden vermeld.

\subsection{Het wettelijke repertoire is niet toereikend}

Het is een heel repertoire. Toch is het niet voldoende voor een goed inzicht in de risico's waarmee een onderneming wordt geconfronteerd en in de wijze waarop deze risico's door de ondernemingsleiding worden tegemoet getreden.

De ontoereikendheid komt onder andere voort uit de fragmentatie in de jaarrekening van wat een samenhangend complex is van activa en passiva, van baten en lasten. Zonder twijfel is informatie over de afzonderlijke fragmenten van groot belang, maar dat wil niet zeggen dat daarnaast informatie over de waarde van het complex als geheel overbodig zou zijn. Je zou kunnen zeggen dat de boekwaarde wel de omvang van het vermogen geeft maar niet de waarde ervan. De uitermate beperkte betekenis die gezaghebbende auteurs al twintig jaar geleden aan boekwaarde toekenden, is trouwens al eerder gememoreerd. Hun conclusie van destijds krijgt in onze tijd nog meer zeggingskracht nu met de huidige mogelijkheden wordt voorbijgegaan aan het wezenlijke element dat 'off balance sheet'-financiering heden ten dage is. Daartoe hoort een belangrijk deel van het recentelijk ontwikkelde financiële instrumentarium.

\subsection{Een voorbeeld}

Het keurslijf van fragmentatie waartoe de aanvaardbare waarderingsgrondslagen van dit moment dwingen, doet zich niet alleen voelen voor het gehele ondernemingscomplex. Ook voor 'on balance sheet'- instrumenten zoals bijvoorbeeld opties stelt de wet een waarderingsmethode verplicht die lang niet altijd recht doet aan de toepassing van het instrument.Dat heeft tot gevolg dat economen en accountants hier wel zeer verschillende wegen moeten gaan. In plaats van mij hierbij neer te leggen, pleit ik voor aanpassing van wat volgens de wet aanvaardbare waarderingsgrondslagen zijn.

Het volgende citaat (Optiebeurs/KPMG, 1989, p. 36) ondersteunt mijn standpunt. Het citaat heeft betrekking op de waardering en resultaatbepaling van gekochte opties indien er tevens een positie is in onderliggende waarden en de situatie niet de professionele handel betreft (geen banken, enzovoort waarvoor andere mogelijkheden bestaan). Het gaat om een typisch probleem.

'Een belangrijk motief voor het kopen van opties kan zijn hət dekken van prijsrisico's (hedging) die worden gelopen over een in onderliggende waarden aangegane positie. Deze positie in onderliggende waarden kan zowel long als short zijn.

Afzonderlijke waardering van de onderliggende waarden en opties waarbij de ongerealiseerde winsten niet tot het resultaat van de verstreken periode worden gerekend maar de ongerealiseerde verliezen wel ten laste van de verstreken periode worden gebracht, roept voor hedge-transacties een matching-probleem op.

Toepassing van de waarderingsgrondslag 'kostprijs of lagere marktwaarde' (artikel 384) zal er namelijk toe kunnen leiden dat ongerealiseerde verliezen ten laste van het verleden worden gebracht terwijl de gecompenseerde bate pas op een later tijdstip wordt verantwoord. ... Dit matching-probleem doet zich niet voor indien men de optie en de onderliggende waarde beide op basis van marktwaarde waardeert waardoor automatisch compensatie van winsten en verliezen zal plaatsvinden.'

Het laatste is een probleem, tenzij men gebruik zou willen maken van wat in zo'n toepassing toch echt als een 'escape'-bepaling zou moeten worden gezien, namelijk dat men een beroep doet op BW 2, titel 9, artikel 362, lid 4: 'Indien dit noodzakelijk is voor het verschaffen van dat inzicht, wijkt de rechtspersoon van die voorschriften af'.

Laten wij voor het niet bijzondere, niet individuele geval maar liever goede voorschriften ontwerpen. 


\section{Marktwaarde}

Hiermee is voor een vlottend financieel actief het woord 'marktwaarde' dan toch gevallen. Gebruik van marktwaarde is in de jaren negentig gemakkelijker te accepteren dan twintig jaar geleden.

Door een veel beter ontwikkeld instrumentarium zijn de financiële markten vollediger, perfecter en efficiënter geworden. De toegenomen betrouwbaarheid van de prijsvorming op die markten is van grote betekenis voor de aanvaardbaarheid van marktprijzen als grondslag voor waardering. Tegelijkertijd is, met de toegenomen risico's waarmee ondernemers en financiers zijn geconfronteerd, de betekenis van historische prijzen afgenomen. Aan de beweeglijkheid op die markten wordt veel minder dan weleer recht gedaan door de toepassing van betrekkelijk onveranderlijke historische 'waarden'.

Toegepast op het optie-voorbeeld geeft gebruik van marktwaarde de oplossing voor een matching-probleem dat met de op dit moment in accountancy aanvaardbare grondslagen niet zodanig wordt opgelost dat een verantwoord oordeel kan worden gevormd over het rendement en het risico van de onderneming. Het brengt mij tot mijn voorstel om artikel 384 zodanig te wijzigen dat voor vlottende financiële activa ook waardering tegen marktwaarde tot de mogelijkheden behoort.

Duidelijk zal zijn dat ik graag nog wat verder wil gaan en waardering tegen marktwaarde voor de hele onderneming voorstel. In een praktische uitwerking zou het erop neer kunnen komen dat voor de vermogenscomponenten aan de passiefzijde van de balans marktwaarden worden gegeven met in vergelijking tot de boekwaarden van de overige balansposten een post goodwill, respectievelijk badwill. Het zou een verslaggeving opleveren over twee sporen. In het kader van 'refleXXie op twintig jaar wetgeving' - het thema van het $f$ ma-congres - zou hiermee een nieuwe inhoud zijn gegeven aan het tweesporenbeleid zoals dat destijds werd gepropageerd. Destijds waren het de sporen van historische prijzen en actuele waarde. Nu zou het gaan om de sporen van boekwaarde en marktwaarde. De start kan bescheiden zijn: aanpassing van artikel 384 zodat marktwaarden ook voor vlottende financiële activa aanvaardbaar zijn.

\section{Literatuur}

Bergsma, S., De voorstellen van de Commissie-Verdam, Maandblad voor Accountancy en Bedrijfshuishoudkunde, mei 1965.

Goudeket, A., Goed koopmansgebruik, Maandblad voor Accountancy en Bedrijfsuishoudkunde, september 1965

Groeneveld, G. L., De jaarverslaggeving volgens het rapport van de Commisie-Verdam, bezien vanuit het gezichtspunt van de accountant, De Naamlooze Vennootschap, april/mei 1965.

Groeneveld, G. L., Het ontwerp van wet op de jaarrekening van ondernemingen, Tijdschrift voor Vennootschappen, Verenigingen en Stichtingen, juni, 1968.

Meer, R. A. H. van der, Embedded value accounting: oude wijn in nieuwe zakken, fma kroniek 1990, redactie C. D. Knoops, J. Dijksma en W. M. du Pon, Groningen, 1990.

Optiebeurs/KPMG, Opties en jaarrekening, 1989

Rapport van de Commissie ingesteld bij beschikking van de minister van Justitie van 8 april 1960 (de Commissie-Verdam), Herziening van het ondernemingsrecht, 's-Gravenhage, 1965.

Sanders, P., Groeneveld, G. L. en Burgert, R., De jaarrekening nieuwe stijl, Samsom, Alphen aan den Rijn, 1972.

Ysselmuiden, Th. S., De nieuwe wetsontwerpen vennootschapsrecht, de jaarrekening van ondernemingen en de herziening van het enquêterecht, 1968.

\section{Noten}

1 Dit artikel is gebaseerd op de inleiding die onder gelijknamige titel werd gehouden in het kader van het tweede $f$ ma-congres. Het motto voor het congres luidde: 'Reflexxie op twintig jaar Nederlandse wetgeving voor jaarrekeningen van ondernemingen". Dit thema biedt ruimte voor beschouwing van wat de destijdse Wet op de Jaarrekening heeft gebracht. Misschien nog interessanter is om na te gaan wat hij niet heeft gebracht. Vooral door het laatste te doen, kan reflectie leiden tot de formulering van wenselijkheden met betrekking tot de inhoud van de wet.

In dit opzicht heeft reflectie een legitimerende kracht.

Wellicht moet ik daarop voor deze beschouwing een beroep doen. Mooier is het als ik aan het slot van mijn beschouwing niet alleen daarop ben aangewezen.

2 Met deze formulering worden verschillen tussen winst en cashflow over het hoofd gezien.

3 Navraag bij de Heer W. Lelieveld, Technisch Directeur van de Centraal Uitvoerende Dienst van PTT Telecom Kabel- en

Radioverbindingen, leert dat een spreadsheet van $30 \mathrm{~Kb}( \pm 3$ schermen groot) met de tussenstops in de financiële centra van New York en Tokio in 54 seconden rond de wereld kan gaan. In 80 seconden kan ook Londen moeiteloos worden aangedaan. 